\title{
Textural analysis of Nuclear Mitotic Apparatus antigen (NuMA) spatial distribution in interphase nuclei from human drug-resistant CEM lymphoblasts
}

\author{
Naima Rafki-Beljebbar ${ }^{\mathrm{a}}$, \\ Françoise Liautaud-Roger ${ }^{\mathrm{b}}$, \\ Dominique Ploton ${ }^{\mathrm{a}}$ and Jean Dufer ${ }^{\mathrm{a}, *}$ \\ ${ }^{a}$ Unité MéDIAN, EA2063, IFR 53, Faculté de \\ Pharmacie, Université de Reims, 51 rue Cognacq-Jay, \\ Reims, France \\ ${ }^{\mathrm{b}}$ Institut Jean-Godinot, 1, rue Gal Koenig, Reims, \\ France
}

Received 15 October 1998

Accepted 2 July 1999

In tumour cell lines, the resistance of cancer cells to a variety of structurally unrelated chemotherapeutic drugs is termed multidrug-resistance or MDR. We reported previously [6] that MDR leukemic cells displayed nuclear texture changes, as assessed by image cytometry. The nature of these changes remained uncertain but they could be associated with alterations of the nuclear matrix which could serve an important role in DNA organization and chromatin structure. Therefore, we have compared the textural features observed in $\mathrm{G}_{0} / \mathrm{G}_{1}$ nuclei from human leukemic CEM cells and their MDR variant CEM-VLB, after staining of either DNA by Feulgen method or nuclear matrix by immunodetection of NuMA antigen on DNase treated samples. Chromatin or NuMA distributions within the nucleus were evaluated by image cytometry. Changes in textural parameters indicate that modifications of NuMA distribution observed in MDR cells are parallel to those observed at the whole chromatin level (i.e., a more decondensed and coarse texture with increase of Energy and Long-run sections and decrease of Contrast and Short-run sections). Moreover, Optical Densities measurements indicate that MDR cells seem to contain less

\footnotetext{
${ }^{*}$ Correspondence to: Jean Dufer, Laboratoire de Physiologie Cellulaire, UFR de Pharmacie, 51, rue Cognacq-Jay, F-51100 Reims, France. Tel.: +33 3269135 90; Fax: +33 3269180 15; E-mail: jean.dufer@univ-reims.fr.
}

NuMA, a datum confirmed by immunoblotting of nuclear proteins. In conclusion, chromatin changes observed by image cytometry in drug-resistant human leukemic CEM cells appear associated with modifications of the nuclear matrix structure.

Keywords: NuMA, nuclear matrix, drug resistance, texture, image analysis

\section{Introduction}

The development of resistance to chemotherapeutic agents is a limiting factor in the management of neoplastic diseases and results in treatment failure. One type of resistance, induced by structurally unrelated drugs, such as vinca alkaloids, anthracyclins, epipodophyllotoxins, or taxanes, is termed multidrugresistance (MDR). The mechanisms underlying this phenomenon have been widely studied using in vitro models, and MDR appears as a complex and multifactorial process [20]. In many tumour cell lines with acquired MDR, drug resistance is associated with the expression of a membrane protein, P-glycoprotein (P-gp), the product of the $m d r l$ gene. This protein acts as an energy dependent efflux pump preventing accumulation of the drug in the cell [10]. However, other mechanisms of MDR have been described and, in some cells, several mechanisms may operate simultaneously [20]. This multifactorial process led to the suggestion that these complex actions might have multiple consequences on the MDR cell phenotype. Indeed, cellular concomitants of MDR are numerous but less information is currently available on the cytological changes associated with MDR. Among them, specific cytological alterations, as evaluated by image cytometry were reported in animal and human MDR cells [5, $16,17,22]$. Most of these alterations concerned the nu- 
clear texture which accounts for the condensation and distribution of the chromatin within the nucleus. They were not provoked by $m d r l$ gene overexpression alone but appeared to be merely a consequence of other alterations occurring during selection of cells by cytotoxic drugs [6]. However, these alterations could have consequences on cell functions as they appear associated with a different sensitivity of chromatin to enzymatic digestion [31].

The nature of these additional changes remains unknown, but one possibility could be the presence of alterations of the nuclear matrix which could serve an important role in DNA organization and chromatin structure. Among matrix proteins, Nuclear Mitotic Apparatus Antigen (NuMA) [18] is a 236-240$\mathrm{kDa}$ phosphoprotein coded by genes on chromosome $11 \mathrm{q} 13$ [27]. It consists of a central rod domain (207 nm $-90 \% \alpha$-helical) flanked by globular end domains and forms one of the longest coiled-coil currently known [12]. This antigen is distributed in the nucleus during interphase but translocates to the spindle poles in mitosis [4]. In interphase nuclei, NuMA is found on a subset of "core" filaments of the nuclear matrix [32] and appears to be present on the "diffuse skeleton" of the matrix [14]. NuMA plays a functional role in the organization of the microtubules of the mitotic spindle [7]. It appears to be a structural support to the nucleus during interphase and represents the structural component involved in the association of the pre-mRNA splicing apparatus with the nucleoskeleton [33].

In order to evaluate a role for the nuclear matrix in the chromatin textural alterations observed in MDR cells, we investigated by image cytometry the distribution of NuMA antigen in interphase nuclei from MDR cells.

\section{Material and methods}

\subsection{Cells}

Lymphoblastic leukemia CCRF-CEM and CEM/ VLB100 (MDR) cells were obtained from W.T. Beck, Memphis, TN and Z. Steplewski, Philadelphia, PA, respectively. These were maintained in RPMI-1640 (Gibco, Grand Island, NY) containing 10\% FCS (Gibco) in a $5 \% \mathrm{CO}_{2}$ atmosphere at $37^{\circ} \mathrm{C}$. CEM-VLB were grown in the presence of $0.4 \mu \mathrm{g} \cdot \mathrm{ml}^{-1}$ vinblastin. All experiments with resistant cells were performed on cells cultured in drug-free medium for more than $48 \mathrm{~h}$. Resistance indices of these cells have been previously reported [6].

\subsection{DNA staining}

Cells in the exponential growth phase were smeared by cytocentrifugation (Shandon cytospin, Life Science Intern., Eragny, France) and air dried. Cell smears were fixed in an alcohol/formalin mixture $(3: 1)$ for $10 \mathrm{~min}$. Hydrolysis was performed in $5 \mathrm{~N} \mathrm{HCl}$ for $30 \mathrm{~min}$ at $22^{\circ} \mathrm{C}$. The cells were then stained in freshly prepared Schiff's reagent (pararosanilin chloride, C.I. 42500, Gürr, BDH, Poole, UK, 0.5\% (w/v) in sulphite water) for $2 \mathrm{~h}$ in the dark at $22^{\circ} \mathrm{C}$. After rinsing in sulphite water and distilled water, the samples were mounted in Acryptol (refraction index: 1.5, Surgipath, Richmond, Canada).

\subsection{NuMA staining}

Cells in exponential growth phase were synchronized by incubation with thymidine ( $2 \mathrm{mM}, 12 \mathrm{~h}$ ), washed, incubated in culture medium for 8-10 h and smeared by cytocentrifugation. After treatment about $85 \%$ of cells were in $\mathrm{G}_{0} / \mathrm{G}_{1}$ phase. Before NuMA staining, DNA was removed from preparations by treatment with DNase I (Boehringer, Mannheim, Germany) $200 \mu \mathrm{g} \cdot \mathrm{ml}^{-1}$ in buffer $(100 \mathrm{mM} \mathrm{NaCl}, 10 \mathrm{mM}$ Pipes, $\mathrm{pH}$ 6.8, $300 \mathrm{mM}$ sucrose, $3 \mathrm{mM} \mathrm{MgCl}_{2}, 4 \mathrm{mM}$ vanadyl riboside complex, $10 \mathrm{mM}$ leupeptin, $1.2 \mathrm{mM}$ PMSF, $0.5 \%$ Triton $\times 100(50 \mu \mathrm{l}$ per slide $))$ for $5 \mathrm{~min}$ [13]. Quality of DNA removal was checked on randomly selected slides by Feulgen staining and image cytometry.

Cells were then fixed in cold acetone for $5 \mathrm{~min}$. Endogenous peroxidase was blocked by preincubating slides in $3 \% \mathrm{H}_{2} \mathrm{O}_{2}$ for $5 \mathrm{~min}$, followed by a $3 \% \mathrm{BSA}$ wash for $20 \mathrm{~min}$. Slides were then incubated overnight in the presence of anti-NuMA-1 primary antibody (Oncogene Science, Cambridge, MA) at $10 \mu \mathrm{g} \cdot \mathrm{ml}^{-1}$ in $0.5 \% \mathrm{BSA}$ at $4^{\circ} \mathrm{C}$. Antibody fixation was revealed either with FITC labelled goat anti-mouse Ig (1:40, $1 \mathrm{~h}, \mathrm{RT}$ ) or peroxidase labelled antibody (Jackson Immunoresearch, West Grove, PA - same conditions) followed by DAB staining.

\subsection{Image cytometry}

After DNA or NuMA staining, image cytometry was performed with an image analysis system (SAMBA 2005, Unilog, Grenoble, France) coupled to a colour 3CCD camera (XC-007P, Sony, Japan) and a microscope (Axioskop, Karl Zeiss, Oberkochen, Germany). Measurements were made with a plan-achromat $\times 40$ objective. At least 200 cells were analyzed on each 
microscope slide and three separate experiments were performed. Twelve parameters were computed from each nuclear image: two geometric features (nuclear area and nuclear perimeter), one densitometric feature (integrated optical density IOD), and nine textural parameters. As the camera interface provides an optical density image at the acquisition step, the IOD is the summation of all pixels in the image in the nucleus and quantitatively measures the total intensity of staining by the DNA- or NuMA binding dye. Because DNA staining with Feulgen reaction was stoichiometric, DNA-IOD was directly related to the total nuclear DNA content. The distribution of nuclei according to DNA-IOD was plotted to provide cell-cycle distribution. The margins defining $\mathrm{G}_{0} \mathrm{G}_{1}$ and $\mathrm{G}_{2}$ peaks were defined as modal IOD $\pm 15 \%$ [6]. At least 100 reference cells (mouse hepatocytes or human lymphocytes) were measured under the same conditions for the calibration of the normal diploid (2c) value. Nine textural features were calculated on the nuclear image after reduction to 16 grey levels by linear rescaling. Four features were calculated on the grey-level cooccurrence matrix: local mean of grey levels (LM), energy (E), entropy (ENT), and inertia (I). Five parameters were calculated on the run-length matrix: short run-length emphasis (SRE), long run-length emphasis (LRE), grey level distribution (GLD), run-length distribution (RLD), and run-length percentage (RPC) [8, $9,11]$.

Univariate analysis was used to obtain the distribution, mean and SD of the nuclear parameters for each cell population. For a given parameter, histograms were computed and the significance of the differences between histograms from various cell populations was calculated using the non parametric KolmogorovSmirnov test on cumulative frequencies. For comparison between different cell lines and staining techniques, variations between sensitive and resistant cells were expressed as the deviation index, according to the formula: $\mathrm{DI}=$ (Value in resistant cells/Value in sensitive cells) -1 . This index value is 0 if no variation occurs between cells [6].

\subsection{Immunoblotting}

Proteins from lysed cells were separated by $12.5 \%$ SDS-PAGE and transferred to a nitrocellulose membrane (Biorad, Hercules, CA). Nitrocellulose sheets were blocked with Tris buffer containing $0.5 \%$ non fat dry milk and $0.1 \%$ Tween 20 for $2 \mathrm{~h}$, incubated overnight at $4^{\circ} \mathrm{C}$ with $10 \mu \mathrm{g} \cdot \mathrm{ml}^{-1}$ anti-NuMA-1, washed 5 times, and incubated with HRP-conjugated goat antimouse antibody $(1: 2000$, Calbiochem, La Jolla, CA). After 5 final washes, proteins were visualized by an ECL chemoluminescence system (Amersham, Les Ulis, France) [25].

\section{Results}

\subsection{DNA content}

The DNA content of the sensitive and resistant CEM cell sublines was estimated by measurement of the Integrated Optical Density (IOD) of cell nuclei stained by the Feulgen method and appears in Fig. 1. The DNA-IOD modal value (i.e., the location of the major peak of the DNA histogram) decreased significantly in the resistant cell line as compared to sensitive counterparts. Moreover, in these CEM cells, drug-resistance is associated with a decrease in cells with very high DNA content, more than $5 \mathrm{c}$. However, this decrease in DNAIOD values in resistant cells obtained by drug-selection was not accompanied by variations in the distribution of cells among the cell cycle phases (data not shown).

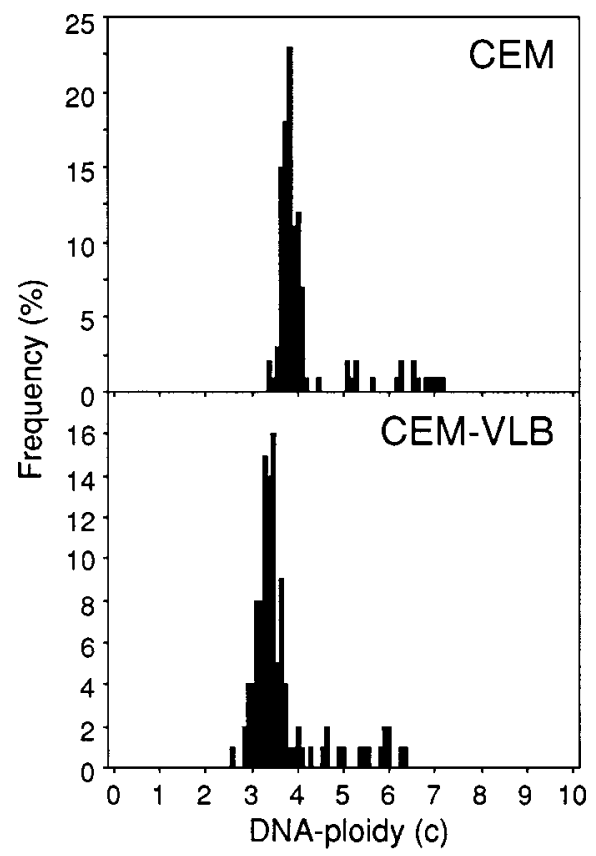

Fig. 1. DNA histograms in drug-sensitive CEM and drug-resistant CEM-VLB cells. DNA distributions in the two cell populations are significantly different ( $p<0.001$, Kolmogorov-Smirnov test on cumulated frequencies). 


\subsection{Nuclear texture analysis after DNA staining}

Textural features estimated by image cytometry are closely related to the location of a given cell in the cell cycle. Comparisons of texture have therefore been performed on cells selected within a given cycle phase. For this purpose, $\mathrm{G}_{0} / \mathrm{G}_{1}$ cells have been isolated on the basis of their DNA-IOD value and analyzed for chromatin texture. The results appear in Fig. 2. The total numbers of analyzed cells were 296 and 268 for CEM and CEM-VLB, respectively. CEM-VLB drugresistant cells display significant variations of nuclear texture as compared with sensitive cells: a more decondensed chromatin (decrease of LM, ENT and I), with

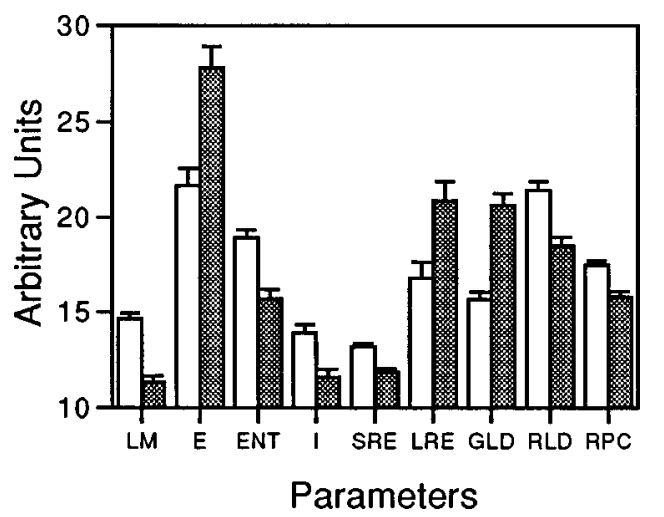

Fig. 2. Texture parameters values in Feulgen-stained $G_{0} / G_{1}$ nuclei from drug-sensitive CEM and drug-resistant CEM-VLB cells. Each bar represents mean + SEM of parameter value in cells. White columns, sensitive cells; Grey columns, drug-resistant cells. For all these parameters, distributions in sensitive and resistant cells are significantly different $(p<0.01$, Kolmogorov-Smirnov test on cumulated frequencies). an increase in the distance between isodensity points (decrease of SRE and increase of LRE) confirming the appearance of a coarse chromatin texture with more homogeneous distribution of chromatin within the nucleus (increase of GLD measuring the uniformity of distribution of optical densities).

\subsection{Nuclear texture analysis after NuMA staining}

NuMA distribution was highly correlated with cell position within the cell cycle. For example, distribution is very different between interphase and mitotic cells (Fig. 3). For these reasons, NuMA textural analysis was performed on cells synchronized in $G_{1}$ phase by thymidine block. Results of staining and of nuclear texture analysis after immunocytochemical NuMA staining of these cells appear in Figs 4 and 5. When compared to the data obtained on Feulgen stained nuclei, NuMA texture measured in drug-resistant CEM-VLB cells, and expressed as deviation index from sensitive cells' values, display modifications similar to those observed in the whole chromatin after DNA staining (Fig. 5A). Moreover, these alterations could be also observed in cell nuclei pretreated with DNAse I (Fig. 5B), indicating that DNA does not seem to play a significant role in these changes. These spatial changes are not related to alterations in nuclear geometry, as surface and perimeter remain unchanged $(28.8 \pm 0.7$ and $3.0 \pm 0.1$ in CEM, $27.8 \pm 0.6$ and $3.0 \pm 0.1$ in CEM-VLB, respectively - NS)

Finally, when NuMA expression was analysed by immunoblotting, drug-resistant CEM-VLB displayed a lower level of expression of this nuclear matrix protein (Fig. 6). Although the immunocytochemical staining
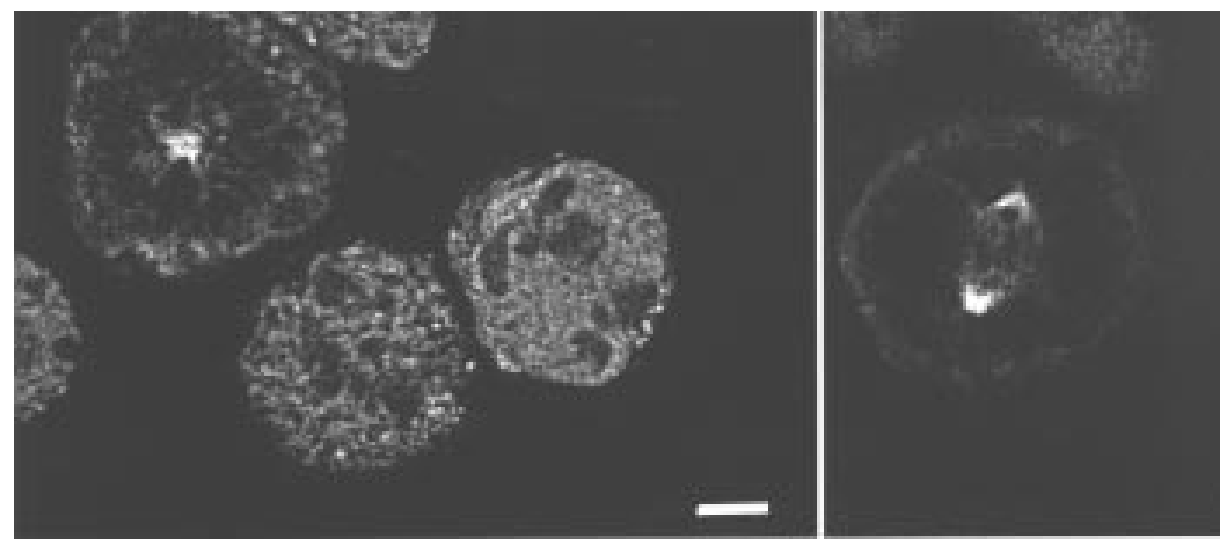

Fig. 3. Detection of NuMA antigen by immunofluorescence and confocal microscopy in interphase and mitotic CEM sensitive cells. NuMA was detected without prior DNase treatment using anti-NuMA-1 monoclonal antibody and FITC-labelled goat anti-mouse secondary antibody. Cells were observed on a Biorad MRC 600 confocal microscope. Left panel: two interphase and a mitotic cell. Right panel: one mitotic cell. 

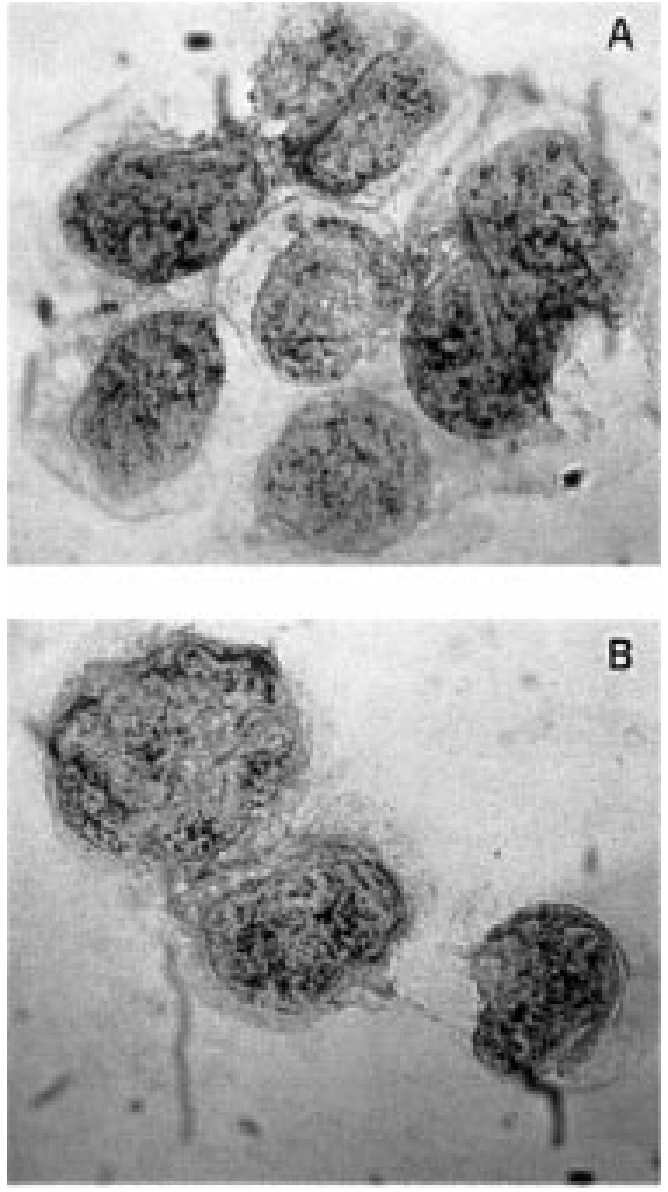

Fig. 4. Detection of NuMA antigen by immunocytochemistry in nuclei from drug-sensitive and drug-resistant CEM cells. NuMA was detected on synchronized cells, without prior DNase treatment, using anti-NuMA-1 monoclonal antibody and peroxidase-labelled goat anti-mouse secondary antibody. Texture analysis of NuMA distribution was performed by absorbtion cytometry on these stained nuclei. Magnification $\times 400$. A: sensitive cells. B: resistant cells.

was not strictly quantitative, this data was confirmed by the values of the Integrated Optical Densities of NuMA staining which were consistently lower in drugresistant cells (Table 1) when compared to the values observed in the drug-sensitive counterparts.

\section{Discussion}

Previous studies in human and animal MDR sublines have revealed numerous phenotypic alterations (for a review, see [2]). Among these alterations, the consequences of the resistance on the cellular morphology are still unclear. At this cytological level, we previously studied the phenotype of several hu-

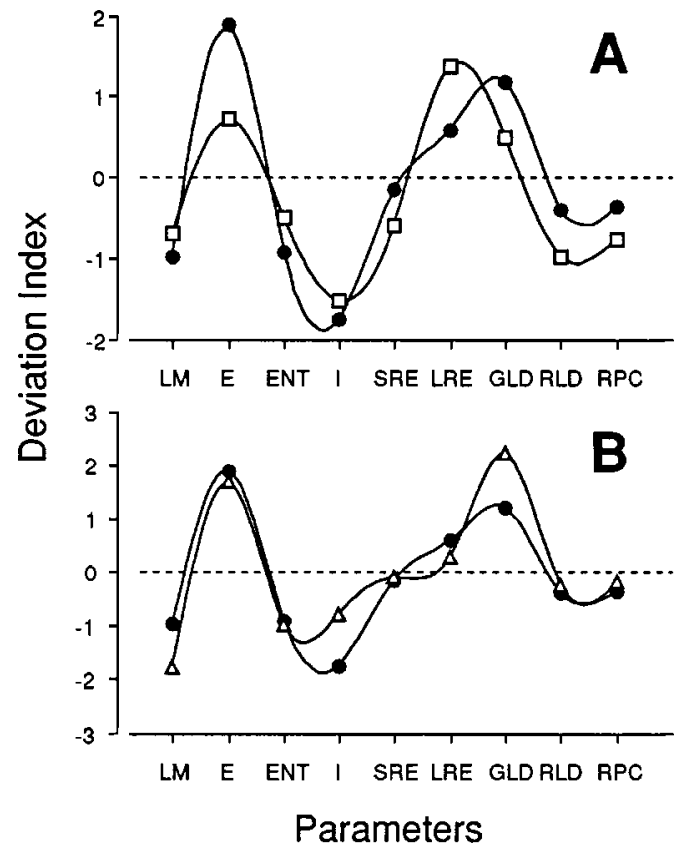

Fig. 5. Variations of textural parameters in $G_{0} / G_{1}$ drug resistant CEM-VLB cells. Variations are expressed as deviation indices, as described in Material and methods. Panel A: $\square$ DNA staining; - NuMA staining. Panel B: NuMA staining without $(\bullet)$ or after $(\triangle)$ DNase I digestion of nuclei. Please note that the connecting lines between single unrelated parameters values were added for better legibility only in order to define a visually accessible nuclear "profile".

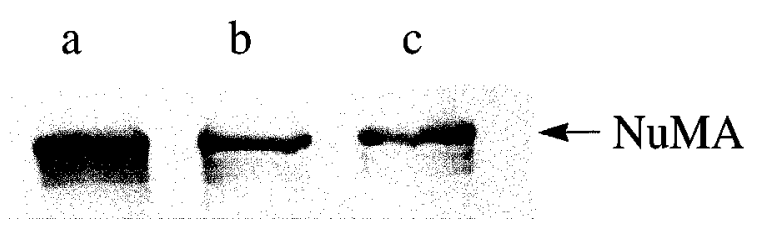

Fig. 6. Immunoblot analysis of NuMA. Nuclear proteins from CEM cells (lane a), and CEM-VLB cells grown in presence (lane b) or absence (lane c) of vinblastin were resolved by SDS-PAGE, transferred to nitrocellulose membranes, and probed with anti-NuMA-1 monoclonal antibody.

Table 1

Integrated Optical Densities of drug-sensitive and -resistant CEM cell nuclei after immunocytochemical NuMA staining

\begin{tabular}{lcc}
\hline Cell population & $\begin{array}{c}\text { Number of cells } \\
\text { analyzed }\end{array}$ & $\begin{array}{c}\text { IOD after NuMA } \\
\text { staining }^{\mathrm{a}}\end{array}$ \\
\hline CEM & 196 & $3.93 \pm 0.12$ \\
CEM-VLB & 177 & $3.37 \pm 0.09^{\mathrm{b}}$ \\
\hline
\end{tabular}

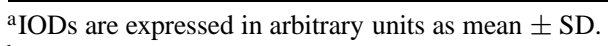

${ }^{\mathrm{b}} p<0.001$ (Kolmogorov-Smirnov test on cumulated frequencies). 
man MDR cell lines. We showed that MDR cell lines obtained by drug selection displayed decreased DNA Feulgen stainability and a decondensation of chromatin with small but compact chromatin clumps [6]. The variations we observed in this study in CEM-VLB cells are similar to those previously described in these and other MDR cell lines (K562-Dox and HL60-Vinc).

As these changes did not appear to be associated with microphotometric negative errors related to progressive heterochromatization or to alterations of DNA lability [21], we tried to evaluate a role for nuclear matrix in these textural modifications. Such an implication could be suspected because, in rat resistant cells, resistance to chlorambucil was accompanied by a reduction of phosphoproteins in the nuclear matrix [28].

This nuclear matrix has been supposed to provide structural support for the nucleus and to play a role in the spatial organization of the genome and in the control of DNA replication and transcription [1].

Numerous studies have been devoted to the characterization of nuclear matrix in normal and neoplastic cells, either by biochemical or ultrastructural methods [15,23]. However, according to Brasch [3], it could be difficult to relate structure directly with biochemical characterization of the nuclear matrix fraction. Therefore, one analytical approach whereby isolation artifacts should be minimized is to monitor individual nuclear proteins in situ by immunomicroscopy, using monoclonal antibodies. Moreover, this approach could be optimized by using computer image analysis [1].

Taking these points into account we have analyzed directly by image cytometry the spatial distribution of NuMA in the nuclei from drug-sensitive and drugresistant leukemic cells. This antigen has been chosen because numerous data support the possibility that NuMA serves a structural function either in the nucleus during interphase or at the polar ends of the mitotic spindle [7,14,26,33]. In this study, we observed that changes in NuMA texture in interphase MDR cells were similar to those observed at the whole chromatin level. These data suggest that previously observed nuclear changes could be explained by alterations of the higher order DNA organization mediated by the nuclear matrix. Moreover, a decrease in NuMA expression was observed in these MDR cells. Interestingly, in radioresistant rat embryonal cells, a progressive loss of nuclear matrix-associated proteins was observed, which correlated with increasing radioresistance and tumourigenicity in these cell lines. These authors therefore suggested that increased resistance as- sociated with increasing tumourigenicity could be due to changes in nuclear matrix-mediated DNA organization [19]. Similarly, a significant decrease in nuclear matrix-associated topoisomerase II has been described in drug-resistant $\mathrm{CHO}$ cells [29].

However, these data on the spatial distribution of NuMA did not preclude changes in the functional characteristics of nuclear matrix, particularly its stability. For example, using DNase I digestion, it was suggested that more differentiated cells have a less stable nuclear matrix while the less differentiated ones have a more stable nuclear matrix. This cell differentiation stage-dependent stability of the nuclear matrix could probably be related to the nuclear activity and gene expression [30]. Since an unstable nuclear matrix may contribute to genetic instability [24] and selective pressure of drug exposure resulted in enhanced genetic stability in resistant cells [28], it could be supposed that nuclear matrix from MDR cells could display increased stability. Work is in progress in our laboratory to assess DNase I sensitivity of nuclear matrices from cell lines with different mechanisms of drug resistance.

In conclusion, chromatin changes observed by image cytometry in drug-resistant human leukemic CEM cells appear associated with modifications of the nuclear matrix structure.

\section{Acknowledgements}

This work was supported by grants from the Comités Départementaux de l'Aube et des Ardennes de la Ligue Française contre le Cancer.

\section{References}

[1] R. Berezney, M.J. Mortillaro, H. Ma, X. Wei and J. Samarabandu, The nuclear matrix: a structural milieu for genomic function, Int. Rev. Cytol. 162A (1995), 1-65.

[2] J.L. Biedler, Drug resistance: genotype versus phenotype Thirty-second G.H.A. Clowes Memorial Award Lecture, Cancer Res. 54 (1994), 666-678

[3] K. Brasch, Drug and metabolite-induced perturbations in nuclear structure and function: a review, Biochem. Cell Biol. 68 (1990), 408-426.

[4] D.A. Compton, I. Szilak and D.W. Cleveland, Primary structure of NuMA, an intranuclear protein that defines a novel pathway for segregation of proteins at mitosis, J. Cell Biol. 116 (1992), 1395-1408. 
[5] J. Dufer, M.G. Akeli, P. Jeannesson, A. Desplaces and J.C. Jardillier, Quantitative morphological analysis of adriamycinresistant human K562 leukemic cells, Cytometry 10 (1989), $37-43$.

[6] J. Dufer, C. Millot-Broglio, Z. Oum'Hamed, F. LiautaudRoger, P. Joly, A. Desplaces and J.C. Jardillier, Nuclear DNA and chromatin texture in multidrug-resistant human leukemic cell lines, Int. J. Cancer 60 (1995), 108-114.

[7] T. Gaglio, A. Saredi and D.A. Compton, NuMA is required for the organization of microtubules into aster-like mitotic arrays, J. Cell Biol. 131 (1995), 693-708.

[8] M.M. Galloway, Texture analysis using gray-level run lengths, Comp. Graph. Image Proc. 4 (1975), 172-179.

[9] F. Giroud, C. Gauvain, D. Seigneurin and V. Von-Hagen, Chromatin texture changes related to proliferation and maturation in erythrocytes, Cytometry 9 (1988), 339-348.

[10] M.M. Gottesman and I. Pastan, Biochemistry of multidrug resistance mediated by the multidrug transporter, Апnи. Rev. Biochem. 62 (1993), 385-427.

[11] R.M. Haralick, K. Shanmugan and I. Dienstein, Textural features for image classification, IEEE Trans. Syst. Man Cyber. SMC 3 (1973), 610-621.

[12] J. Harborth, K. Weber and M. Osborn, Epitope mapping and direct visualization of the parallel, in-register arrangement of the double-stranded coiled-coil in the NuMA protein, EMBO J. 14 (1995), 2447-2460.

[13] D. He, J.A. Nickerson and S. Penman, Core filament of the nuclear matrix, J. Cell Biol. 110 (1990), 569-580.

[14] P. Hozak, The nucleoskeleton and attached activities, Exp. Cell Res. 229 (1996), 267-271.

[15] S.K. Keesee, J.V. Briggman, G. Thill and Y.J. Wu, Utilization of nuclear matrix proteins for cancer diagnosis, Crit. Rev. Eukaryot. Gene Expr. 6 (1996), 189-214.

[16] D. Komitowski, J. Sonka, B. Schmitt and S. Muto, Quantitative description of nuclear morphology in assessing resistance of Sarcoma 180 to adriamycin, Cytometry 8 (1987), 625-631.

[17] D. Komitowski, L.J. Charamella and N.V. Dimitrov, Evaluation of nuclear morphology in adriamycin sensitive and resistant cells, Ann. Clin. Lab. Sci. 24 (1994), 259-265.

[18] B.K. Lydersen and D.E. Pettijohn, Human-specific nuclear protein that associates with the polar region of the mitotic apparatus: distribution in a human/hamster hybrid cell, Cell $\mathbf{2 2}$ (1980), 489-499.

[19] R. Malyapa, W. Wright, Y. Taylor and J. Roti-Roti, DNA supercoiling changes and nuclear matrix-associated proteins: possible role in oncogene-mediated radioresistance, Int. J. Radiat. Biol. Phys. 35 (1996), 963-973.

[20] J.A. Moscow and K.H. Cowan, Multidrug resistance, J. Natl. Cancer Inst. 80 (1988), 14-20.
[21] V. Palissot, F. Liautaud-Roger, Y. Carpentier and J. Dufer, Analysis of DNA content in multidrug-resistant cells by image and flow cytometry, Cell. Prolif. 29 (1996), 549-559.

[22] O. Pauwels and R. Kiss, Computerized morphonuclear analyses of Feulgen-stained nuclei from 11 chemosensitive and from 11 chemoresistant neoplastic cell lines, Anal. Cell. Pathol. 7 (1994), 235-250.

[23] K.J. Pienta, A.W. Parkin and D.S. Coffey, Cancer as a disease of DNA organization and dynamic cell structure, Cancer Res. 49 (1989), 2525-2532.

[24] K.J. Pienta and W.S. Ward, An unstable nuclear matrix may contribute to genetic instability, Med. Hypotheses 42 (1994), $45-52$.

[25] N. Rafki, F. Liautaud-Roger, L. Devy, C. Trentesaux and J. Dufer, P53 protein expression in human multidrug-resistant CEM lymphoblasts, Leuk. Res. 21 (1997), 147-152.

[26] Saredi, L. Howard and D.A. Compton, NuMA assembles into a extensive filamentous structure when expressed in the cell cytoplasm, J. Cell Sci. 109 (1996), 619-630.

[27] C.A. Sparks, P.L. Bangs, G.P. McNeil, J.B. Lawrence and E.G. Fey, Assignment of the nuclear mitotic apparatus protein NuMA gene to human chromosome 11q13, Genomics 17 (1993), 222-224.

[28] K.D. Tew, B.C. Moy and B. Hartley-Asp, Acquired drug resistance is accompanied by modification in the karyotype and nuclear matrix of a rat carcinoma cell line, Exp. Cell Res. 149 (1983), 443-450.

[29] N.I. Valkov, J.L. Gump and D.M. Sullivan, Quantitative immunofluorescence and immunoelectron microscopy of the topoisomerase II alpha associated with nuclear matrices from wild-type and drug-resistant chinese hamster ovary cell lines, J. Cell. Biochem. 67 (1997), 112-130.

[30] L. Yang, E.C. Chew, S.B. Cheng-Chew, H.F. Yam, E.P. Loong and Z.H. Zhai, Electron microscopic analysis of the relationship between nuclear matrix stability and cell differentiation, Anticancer Res. 14 (1994), 2557-2563.

[31] S. Yatouji, C. Trentesaux and J. Dufer, Multidrug-resistance in human ovarian carcinoma cells is associated with nuclear texture changes and DNase I hypersensitivity (abstract), Anal. Cell. Pathol. 18 (1999), 58.

[32] Zeng, D. He and B.R. Brinkley, Localization of NuMA protein isoforms in the nuclear matrix of mammalian cells, Cell Motil. Cytoskel. 29 (1994), 167-176.

[33] Zeng, D. He, S.M. Berget and B.R. Brinkley, Nuclear-mitotic apparatus protein: a structural protein interface between the nucleoskeleton and RNA splicing, Proc. Natl. Acad. Sci. USA 91 (1994), 1505-1509. 


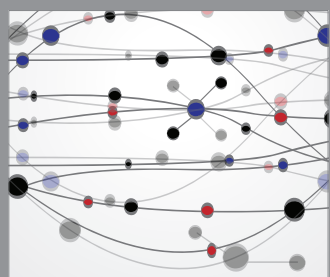

The Scientific World Journal
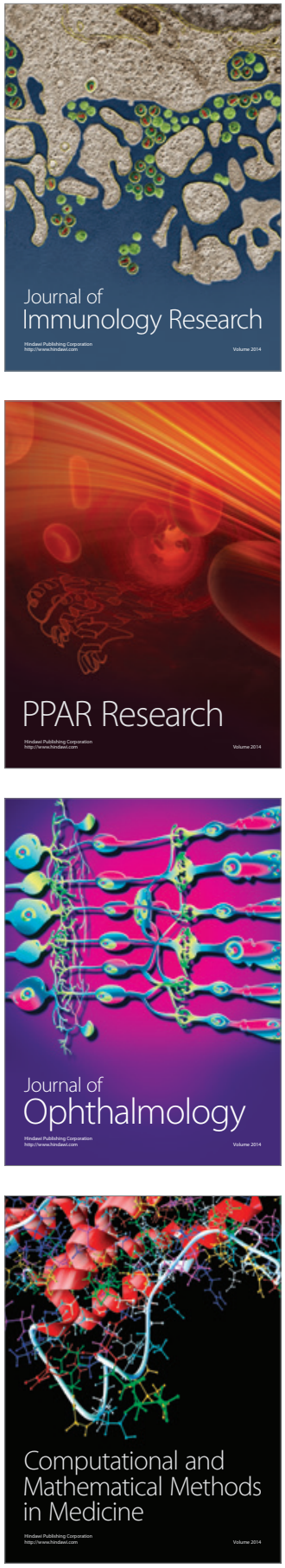

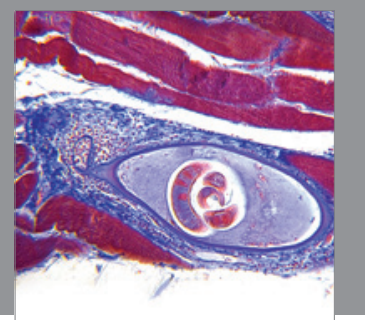

Gastroenterology

Research and Practice
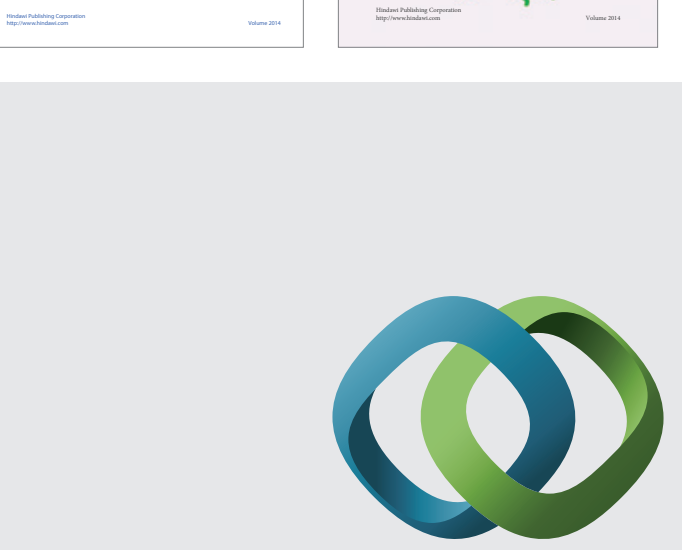

\section{Hindawi}

Submit your manuscripts at

http://www.hindawi.com
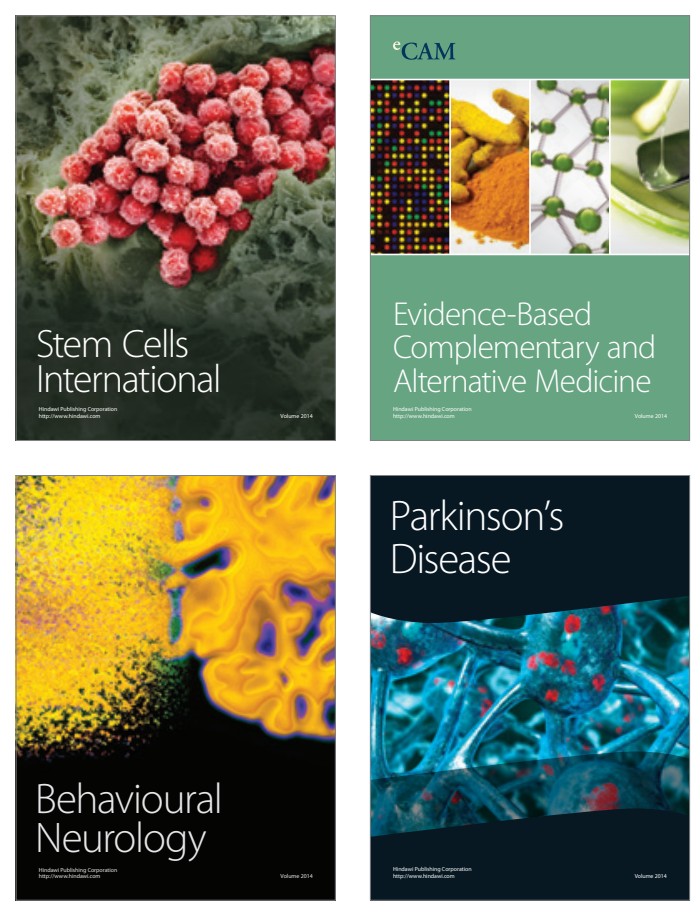

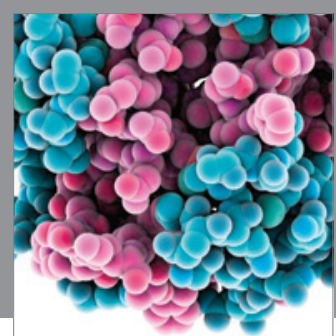

Journal of
Diabetes Research

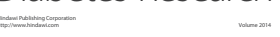

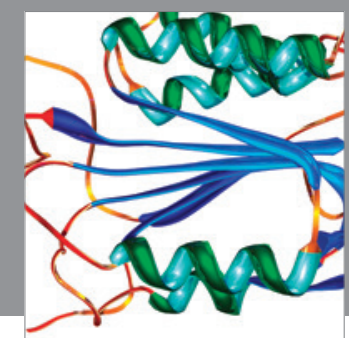

Disease Markers
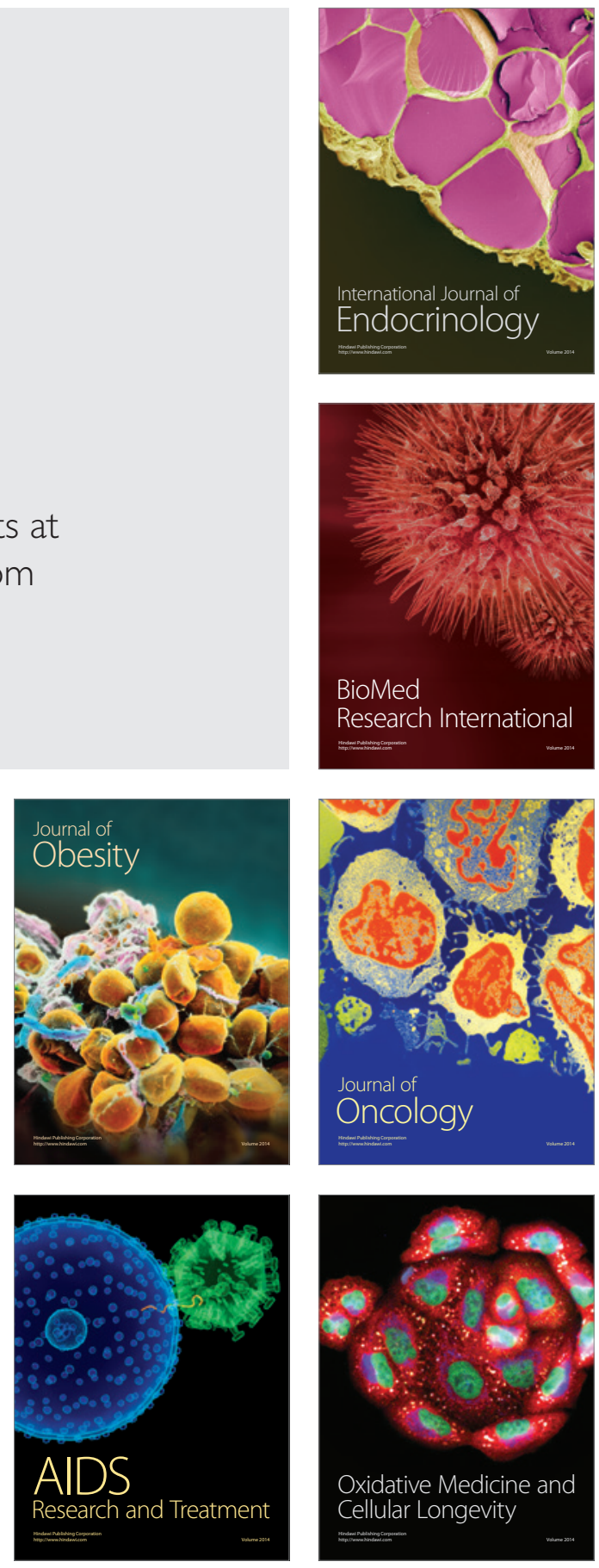